\title{
Breeding for pre-harvest sprouting resistance in bread wheat under rainfed conditions
}

\author{
Muhammad ZEESHAN ${ }^{1}$, Waheed ARSHAD ${ }^{1}$, Muhammad Imran KHAN ${ }^{1}$, Shiraz ALI ${ }^{1}$, Ali NAWAZ ${ }^{1}$, \\ Amina BATOOL ${ }^{1}$, Muhammad TARIQ ${ }^{2}$, Muhammad Imran AKRAM ${ }^{3}$, Muhammad Amjad ALI (凶) ${ }^{4}$ \\ 1 Barani Agricultural Research Station, Fatehjang, Attock 43350, Pakistan \\ 2 Barani Agricultural Research Institute, Chakwal 48800, Pakistan \\ 3 Soil and Water Conservation Research Station, Fatehjang, Attock 43350, Pakistan \\ 4 Department of Plant Pathology and Centre of Agricultural Biochemistry \& Biotechnology, University of Agriculture, \\ Faisalabad 38040, Pakistan
}

\begin{abstract}
Pre-harvest sprouting in wheat is the germination of seeds within the spikes when rains occur after or during grain ripening, which occurs commonly in the barani tract of Pakistan. Therefore, 10 cultivars and five advanced lines of spring bread wheat were evaluated for pre-harvest sprouting resistance. After natural rainfall, seeds were immediately collected from the wet spikes and tested for germinating ability. Three different germination tests were applied to hand-threshed seed: (1) spikes threshed on the day of sampling and germination tested immediately, (2) spikes threshed on the day of sampling and germination tested 1 week later, and (3) spikes threshed 1 week after sampling and germination test immediately after threshing. Seeds and spikes kept for 1 week were place on blotting paper at room temperature. Cultivars BARS-09, 09FJ17, Doukkala-12, NARC-09 and Ouassou-20 exhibited higher sprouting resistance while other genotypes were susceptible to pre-harvest sprouting in each of the three tests. A diallel crossing was conducted with six susceptible and two resistant genotypes to assess the genetic behavior of pre-harvest sprouting resistance. The combining ability (CA) demonstrated a higher proportion of additive genetic effects for sprouting resistance, because of higher variance of general and specific CA for both parameters under study. Doukkala-12 and BARS-09 showed increased pre-harvest sprouting resistance in their $\mathrm{F}_{1}$ descendants.
\end{abstract}

Keywords bread wheat, germination index, general combining ability, pre-harvest sprouting, specific combining ability

Received February 1, 2018; accepted March 15, 2018

Correspondence: amjad.ali@uaf.edu.pk

\section{Introduction}

Pre-harvest sprouting in bread wheat (Triticum aestivum) is a problem that occurs all over the world to varying degrees. The problem occurs when high humidity accompanies rainfall on standing mature wheat crops before harvest, and seeds in the spike germinate. As the consequence of this, wheat quality as well as quantity are affected, reducing nutritional value and yield ${ }^{[1]}$. Many early wheat scientists reported that pre-harvest sprouting is negatively correlated with yield, seed viability, seedling vigor, flour yield and baking quality ${ }^{[1-9]}$. Changes in sugar content, total protein and composition of amino acids accompanied by enzymatic activities are the reasons for the degradation in quality and quantity. Products made from germinated seeds can be spongy, soggy, off-color and of inferior quality as reported by Groos et al. ${ }^{[10]}$. Compact interior and smaller volume breads baked from sprouted seeds are also reported $^{[11]}$. The key reason for this is higher $\alpha$-amylase activity. $\alpha$-Amylases degrade starch, hence producing quality of bread that is below the accepted standards of consumers $^{[12]}$.

Some seed characters have been reported that can enhance sprouting resistance, abridged point of $\alpha$-amylase action, a reduced amount of water assimilation by the grains and the occurrence of inhibitors of germination $^{[10,13-15]}$. Pre-harvest sprouting is determined by environmental conditions, inner factors and interaction between these factors ${ }^{[5,16]}$. The resistance to sprouting is primarily linked with an ample degree of kernel dormancy ${ }^{[17,18]}$. Pre-harvest sprouting depends significantly on (1) genetic traits like kernel coat, shielding structures of spike and straightness of spike, (2) environmental conditions like temperature and rainfall, and 
(3) agronomic aspect like fertilization ${ }^{[15,16,19]}$. With such a wide ranges of factors that contribute to pre-harvest sprouting in the field, it is quite difficult to identify resistant plants. Several methods were devised to measure resistance to sprouting in plants under laboratory conditions, for example germination tests of threshed grains, or whole spikes in sand or on blotting paper, visual assessment of kernels and physiological study of grains for enzymatic alterations ${ }^{[2,6,20]}$. Germination tests of threshed grains or whole spikes indicate the extent of kernel dormancy that is governed by the embryo ${ }^{[2,21]}$. Shorter et al. ${ }^{[22]}$ evaluated some wheat accessions from New Zealand to assess sprouting resistance and reported that exploiting germination index to judge seed dormancy was consistent across years, hence the most consistent forecaster.

Another trait that is linked with pre-harvest sprouting resistance is grain color. Cultivars having red kernels are more resistant to sprouting than white ones ${ }^{[2,23]}$. Therefore, red kernel color is commonly used as an indicator of sprouting resistance in wheat. The general perception of the relationship between grain color and flour extraction is that white kernel grains are more useful than red kernel grains ${ }^{[24]}$. Sprouted products do not receive a good price and are often used to feed animals, resulting in huge financial losses for many farmers and ultimately their countries $^{[9,24]}$. Due to this, improvement of pre-harvest sprouting resistance of white kernel wheat genotypes must be incorporated in the present breeding programs.

The barani (rainfed) tract is one of the important wheat producing areas in the Punjab Province of Pakistan. Low production of wheat in this area also negatively affects the overall production of wheat in the province. Rainfall during the grain maturing phase occurs in many years, causing pre-harvest sprouting and severe harm to wheat production significantly affecting the value of wheat in the local market. This further highlights the importance of breeding for pre-harvest sprouting resistance in wheat. A technique that is helpful for analyzing genetic divergence of particular parameters and to identify hybrids that will provide better segregants was proposed by Griffing ${ }^{[25]}$. Genetic knowledge of pre-harvest sprouting is a prerequisite for a resourceful breeding program to improve the dormancy level of wheat genotypes against pre-harvest sprouting under rainfed conditions.

To understand the genetic basis of pre-harvest sprouting and the required level of dormancy in white kernel cultivars, 15 diverse genotypes of bread wheat were assessed for pre-harvest sprouting resistance and eight genotypes were further analyzed by diallel crossing to identify parents with better combining ability. This study aimed to provide practical information about pre-harvest sprouting resistance in wheat cultivars and to develop white kernel wheat cultivars with innately better sprouting resistance.

\section{Materials and methods}

2.1 Experimental materials, design and evaluation of sprouting resistance

\subsubsection{Experiment 1}

The current study was conducted at the Barani Agricultural Research Station, Fatehjang District Attock, Pakistan. Fifteen genotypes were assessed including six spring wheat cultivars (FSD-08, Dharabi-11, NARC-09, CH-50, BARS-09 and Inqlab-91) that are high yielding, commonly grown and widely accepted by the farmers in the barani tract, Pakistan. Five advanced lines (06FJS3013, 09FJ34, 09FJ21, 05FJS3074 and 09FJ17) in testing phases at different provincial and national levels were also included. The remaining four genotypes (Hamam-4, Hubara-2/ Qafzah-21, Ouassou-20 and Doukkala-12) were selected from the International Centre for Agricultural Research in Dry Areas nurseries. The genotypes, Hamam-4, Hubara-2/ Qafzah-21, Ouassou-20, NARC-09, 09FJ34 and Doukkala-12 are red kernel types, while the others are white kernel types. The experiment was sown in a randomized complete block design (RCBD) with three replicates. The plot size was $7.2 \mathrm{~m}^{2}$ having six rows $4 \mathrm{~m}$ in length with $30 \mathrm{~cm}$ row spacing. This experiment was conducted because of the periods of heavy rainfall $(146 \mathrm{~mm})$ during the ripening months of the wheat crop, i.e., April and May, just before and during the time of harvest. This precipitation is undesirable leaving insufficient time for the grains or spikes to dry before the next rainfall occurs. The total rainfall of the crop season (Nov.-May) was $364 \mathrm{~mm}$.

Germination tests were used to assess pre-harvest sprouting resistance of the wheat genotypes. Tests for pre-harvest sprouting on wet spikes harvested immediately after rainfall were conducted by the method described by Paterson et al. ${ }^{[26]}$. In this test, 50 spikes along with $10 \mathrm{~cm}$ of peduncle were arbitrarily harvested from each plot. Germination of hand-threshed seed was tested in three different ways with two replicates each: $T_{1}$, seed from 15 spikes threshed on the day of sampling tested immediately; $T_{2}$, seed from 15 spikes threshed on the day of sampling tested after being placed blotting paper for 1 week at room temperature; and $T_{3}$, seed from 15 spikes that had been kept for 1 week on blotting paper at room temperate before threshing and tested immediately after threshing.

\subsubsection{Experiment 2}

Eight bread wheat genotypes (Hamam-4, Hubara-2/ Qafzah-21, Dharabi-11, 06FJS3013, 09FJ21, Doukkala12, BARS-09 and Inqlab-91) were selected from the results of the first experiment, based on their diverse sprouting response. To access their combining ability, 
these genotypes were crossed in all possible combinations to obtain all possible offspring. All $56 \mathrm{~F}_{1}$ hybrids from the eight parents were sown on 10 November 2012, in an RCBD with three replicates at the Barani Agricultural Research Station, Fatehjang District Attock, Pakistan. The $\mathrm{F}_{1}$ hybrids along with parents were sown in an area of $1.2 \mathrm{~m}^{2}$ comprised of two rows $2 \mathrm{~m}$ in length with $10 \mathrm{~cm}$ between plants, and $30 \mathrm{~cm}$ between rows. A total of $760 \mathrm{~mm}$ rainfall was recorded during that growing season. All the recommended agronomic and protection measures were carried out for the whole trial.

For assessing sprouting resistance, 10 physiological mature spikes were harvested from each experimental unit for each replicate. To disinfect the spikes, a $1 \%$ solution of bleaching powder was used and spikes were sterilized for 10-15 min. Then, they were soaked in water in a plastic tube, wrapped with plastic film for $4 \mathrm{~h}$, according to the method of Jiang and $\mathrm{Xiao}^{[1]}$ to simulate the effect of natural rainfall on the spikes. After soaking, intact spikes were place on blotting paper to dry beforehand thrashing and bulking, and germination was then tested to determine their pre-harvest sprouting resistance.

\subsection{Germination test}

Germination tests were conducted for both experiments in Petri dishes sterilized with $70 \%$ ethanol and distilled water to avoid contamination of the germinating materials. The germination tests for Experiment 1 were executed in 2012 and for Experiment 2 in 2013, 25 seeds from each of the 15 genotypes from the first experiment and from the second experiment, $56 \mathrm{~F}_{1}$ crosses along with eight parents were kept on a filter paper of $10 \mathrm{~cm}$ diameter in separate Petri dishes. Then, $6 \mathrm{~mL}$ of distilled water was poured into each Petri dish and they were incubated at $20^{\circ} \mathrm{C}, 75 \% \mathrm{RH}$ and 16:8 h L:D photoperiod. Germinated seeds were counted daily for seven consecutive days for all samples. Germination was characterized as coleoptiles emergence from the seeds as described by Hagemann and Ciha ${ }^{[27]}$ (sprouting scale 3 ).

The data were converted to percent germination (PG) and a germination index (GI). The GI was obtained for each experimental unit in Experiment 1 and the $56 \mathrm{~F}_{1}$ crosses and eight parents (Experiment 2) by the equation of Jiang and $\mathrm{Xiao}^{[1]}$.

$$
\begin{aligned}
\mathrm{GI}= & \left(7 \times n_{1}+6 \times n_{2}+5 \times n_{3}+4 \times n_{4}+3 \times n_{5}\right) \\
& \left.+2 \times n_{6}+1 \times n_{7}\right) \times 100 /(\text { number of days }) \\
& \times(\text { total number of seeds })
\end{aligned}
$$

where $n_{1}, n_{2}, \ldots, n_{7}$ represents the number of germinated seeds on day 1 , seeds germinated day 2 through to seeds germinated on day 7 , i.e., 7 days and 25 seeds in this case.

Percentage of germination was the percentage of the total seeds with coleoptile length at least equal to the size of seed out of the total number of seeds examined, as given by Hagemann and Ciha ${ }^{[27]}$.

$$
\mathrm{PG}=(\text { seed counted on days } 1 \text { to } 7) / 25 \times 100
$$

\subsection{Data analysis}

Analysis of variance (ANOVA) of PG and GI was performed using the method provided by Steel et al. ${ }^{[28]}$ and detailed by Muhammad ${ }^{[29]}$. Comparison of means was performed with the Duncan's new multiple range test ${ }^{[30]}$. The variability analysis for combining abilities was calculated by the method of Griffing ${ }^{[25]}$ Method 1 and Model 1 , while including parents, $F_{1}$ progeny and reciprocals.

\section{Results}

\subsection{Selection of plant materials for pre-harvest sprouting} resistance

Th outcome of the ANOVA of germination percentage and index for the 15 genotypes is shown in Table 1. Significant

\begin{tabular}{|c|c|c|c|}
\hline \multirow{2}{*}{ Source of variance } & \multirow{2}{*}{$\mathrm{DF}$} & \multicolumn{2}{|c|}{ Mean square } \\
\hline & & PG & GI \\
\hline Replication & 2 & 7.48 & 16.35 \\
\hline Genotype (G) & 14 & $1069.99 * *$ & $460.09^{* *}$ \\
\hline Error & 28 & 1.96 & 3.97 \\
\hline Treatment $(\mathrm{T})$ & 2 & $36.08 * *$ & $84.19^{* *}$ \\
\hline $\mathrm{G} \times \mathrm{T}$ & 28 & $15.48 * *$ & $13.01 * *$ \\
\hline Error & 60 & 2.31 & 4.71 \\
\hline $\mathrm{CV} / \%$ & & 1.87 & 4.32 \\
\hline
\end{tabular}
divergence was observed between treatments (T) and genotypes (G) for both PG and GI. The interaction between

Table 1 Analysis of variance of PG and GI of 15 spring wheats screened for pre-harvest sprouting resistance

Note: PG, Percent germination; GI, Germination index; **, significant difference at $P<0.01$. 
$\mathrm{G} \times \mathrm{T}$ was also statistically significant for both traits $(P<0.05)$. PG and GI mean values for the 15 genotypes are presented in Table 2 .

Broad ranges and significant variation were observed between the 15 wheat genotypes studied for both traits. Mean values of $P G$ in $T_{3}$ were greater than in $T_{2}$ and $T_{1}$, with statistical difference for $T_{1}$. The mean value of GI in $\mathrm{T}_{1}$ was higher than other treatments. The ranges of $\mathrm{PG}$ were $54 \%$ to $91 \%, 55 \%$ to $90 \%$ and $57 \%$ to $92 \%$ for $\mathrm{T}_{1}, \mathrm{~T}_{2}$ and $\mathrm{T}_{3}$, respectively. Similarly, GI ranged from $35.7 \%$ to $57.6 \%, 33.2 \%$ to $57.3 \%$ and $35.2 \%$ to $57.7 \%$ for $\mathrm{T}_{1}, \mathrm{~T}_{2}$ and $\mathrm{T}_{3}$, respectively. Germination percentage and index values for BARS-09, 09FJ17, Doukkala-12, Ouassou-20 and NARC-09 were lower than other genotypes for $T_{1}, T_{2}$ and $\mathrm{T}_{3}$. However, Inqlab-91, 09FJ21, Hamam-4 and Dharabi11 showed higher PG and GI values.

The average $\mathrm{PG}$ values of white kernel genotypes were $81.4 \%, 82.0 \%$ and $82.3 \%$ for $\mathrm{T}_{1}, \mathrm{~T}_{2}$ and $\mathrm{T}_{3}$, respectively. The red kernel genotypes showed $78.6 \%, 79.4 \%$ and $79.2 \%$ for $\mathrm{T}_{1}, \mathrm{~T}_{2}$ and $\mathrm{T}_{3}$, respectively, for PG. The average GI values in white and red kernel genotypes were $52.3 \%$, $51.0 \%$ and $50.0 \%$, and $47.5 \%, 47.3 \%$, and $47.2 \%$ for $\mathrm{T}_{1}$, $\mathrm{T}_{2}$ and $\mathrm{T}_{3}$, respectively. Grain color is another parameter that influences pre-harvest sprouting resistance. Generally red kernel genotypes are more resistant than the white ones. Lower values of PG and GI of red kernel cultivars compared to the white ones, as recorded in our study, show the relationship between grain color and pre-harvest sprouting resistance.

\subsection{Combining ability studies}

PG and GI results diallel crosses are given in Table 3. Significant differences were observed between all the parents and $F_{1}$ hybrids for both traits under study. The general and specific combining abilities along with their reciprocal effects were statistically significant for both the traits (Table 4). Based on the expected mean square method, variance of general combining ability (GCA) was greater than the variance of specific combining ability (SCA). The higher ratio of GCA compared to SCA for both PG and GI (Table 5) indicates significance of additive genetic effects controlling the inheritance of both these traits.

SCA and GCA estimates are presented in Tables 6-7, respectively. Among the parents, BARS-09 had maximum negative GCA effects on both PG (-12.4) and GI (-10.8). Similarly, Doukkala-12 also had negative GCA effects on both PG (-9.08) and GI (-10.4), whereas the other six parents (Hamam-4, Hubara-2/Qafzah-21, Dharabi-11, 06FJS3013, 09FJ21 and Inqlab-91) had positive GCA effects for both traits under study. Analysis of SCA showed that the hybrids Hubara-2/Qafzah-21 $\times$ Doukkala-12 [-9.97 (PG), -9.71 (GI)] and Hubara-2/Qafzah-21 $\times$ BARS-09 [-7.37 (PG) and $-9.23(\mathrm{GI})]$ had maximum negative SCA effects for both PG and GI. Other crosses that exhibited negative PG and GI values were $09 \mathrm{FJ} 21 \times$ Inqlab-91, 06FJS3013 $\times$ Inqlab-91, Dharabi-11 $\times$ BARS09, Dharabi-11 × 09FJ21 and Hamam-4 × 06FJS3013,

Table 2 Mean PG and GI of 15 spring wheat genotypes screened for pre-harvest sprouting resistance

\begin{tabular}{|c|c|c|c|c|c|c|c|c|}
\hline \multirow{2}{*}{ Genotype } & \multicolumn{4}{|c|}{$\mathrm{PG} / \%$} & \multicolumn{4}{|c|}{$\mathrm{GI} / \%$} \\
\hline & $\mathrm{T}_{1}$ & $\mathrm{~T}_{2}$ & $\mathrm{~T}_{3}$ & Mean & $\mathrm{T}_{1}$ & $\mathrm{~T}_{2}$ & $\mathrm{~T}_{3}$ & Mean \\
\hline$\overline{\text { FSD-08 }}$ & $86.5 \mathrm{a}$ & $86.8 \mathrm{a}$ & $87.1 \mathrm{ab}$ & $86.8 \mathrm{~d}$ & $53.7 \mathrm{ab}$ & $54.0 \mathrm{ab}$ & $52.1 \mathrm{abc}$ & $53.3 \mathrm{~cd}$ \\
\hline Hamam-4 & $89.7 \mathrm{a}$ & $90.2 \mathrm{a}$ & $89.9 \mathrm{ab}$ & $89.9 \mathrm{ab}$ & $57.0 \mathrm{ab}$ & $57.3 \mathrm{a}$ & $56.7 \mathrm{a}$ & $56.8 \mathrm{a}$ \\
\hline Hubara-2/ Qafzah-21 & $87.0 \mathrm{a}$ & $87.0 \mathrm{a}$ & $87.3 \mathrm{ab}$ & $87.1 \mathrm{~d}$ & $53.7 \mathrm{ab}$ & $52.7 \mathrm{~b}$ & $53.3 \mathrm{ab}$ & $53.2 \mathrm{~cd}$ \\
\hline Dharabi-11 & $88.1 \mathrm{a}$ & $88.1 \mathrm{a}$ & $87.8 \mathrm{ab}$ & $88.0 \mathrm{~cd}$ & $56.0 \mathrm{ab}$ & $55.3 \mathrm{ab}$ & $57.7 \mathrm{a}$ & $56.3 \mathrm{a}$ \\
\hline Ouassou-20 & $74.5 \mathrm{c}$ & $75.1 \mathrm{c}$ & $75.2 \mathrm{c}$ & $74.9 \mathrm{f}$ & $45.7 \mathrm{c}$ & $47.4 \mathrm{c}$ & $46.3 \mathrm{~cd}$ & $46.5 \mathrm{e}$ \\
\hline 06FJS3013 & $88.3 \mathrm{a}$ & $89.0 \mathrm{a}$ & $90.0 \mathrm{ab}$ & $89.1 \mathrm{bc}$ & $56.5 \mathrm{ab}$ & $57.3 \mathrm{a}$ & $55.0 \mathrm{ab}$ & $56.3 \mathrm{a}$ \\
\hline NARC-09 & $74.7 \mathrm{c}$ & 75. bc & $77.0 \mathrm{c}$ & $75.8 \mathrm{f}$ & $45.7 \mathrm{c}$ & $46.0 \mathrm{~cd}$ & $45.3 \mathrm{~d}$ & $45.7 \mathrm{e}$ \\
\hline 09FJ34 & $87.4 \mathrm{a}$ & $87.5 \mathrm{a}$ & $87.7 \mathrm{ab}$ & $87.5 \mathrm{~d}$ & $54.1 \mathrm{ab}$ & $52.7 \mathrm{~b}$ & $53.3 \mathrm{ab}$ & $53.4 \mathrm{~cd}$ \\
\hline CH-50 & $86.3 \mathrm{a}$ & $88.1 \mathrm{a}$ & $85.3 \mathrm{~b}$ & $86.6 \mathrm{~d}$ & $54.9 \mathrm{ab}$ & $55.1 \mathrm{ab}$ & $52.0 \mathrm{abc}$ & $54.0 \mathrm{bc}$ \\
\hline 09FJ21 & $90.3 \mathrm{a}$ & $89.5 \mathrm{a}$ & $90.0 \mathrm{ab}$ & $90.1 \mathrm{ab}$ & 57.6 a & $55.3 \mathrm{ab}$ & $55.0 \mathrm{ab}$ & $56.0 \mathrm{ab}$ \\
\hline Doukkala-12 & $67.3 \mathrm{~d}$ & $69.1 \mathrm{~d}$ & $66.7 \mathrm{~d}$ & $67.7 \mathrm{~g}$ & $35.7 \mathrm{~d}$ & $33.2 \mathrm{f}$ & $35.2 \mathrm{e}$ & $34.7 \mathrm{~h}$ \\
\hline 05FJS3074 & $78.8 \mathrm{~b}$ & $79.7 \mathrm{~b}$ & $79.0 \mathrm{c}$ & $79.2 \mathrm{e}$ & $52.8 \mathrm{~b}$ & $52.1 \mathrm{~b}$ & $49.2 \mathrm{bcd}$ & $51.4 \mathrm{~d}$ \\
\hline 09FJ17 & $64.7 \mathrm{~d}$ & $65.7 \mathrm{~d}$ & $67.2 \mathrm{~d}$ & $65.9 \mathrm{~h}$ & $44.7 \mathrm{c}$ & $42.4 \mathrm{~d}$ & $44.0 \mathrm{~d}$ & $43.7 \mathrm{f}$ \\
\hline BARS-09 & $53.7 \mathrm{e}$ & $55.0 \mathrm{e}$ & $57.0 \mathrm{e}$ & $55.2 \mathrm{i}$ & $36.4 \mathrm{~d}$ & $38.5 \mathrm{e}$ & $35.7 \mathrm{e}$ & $36.9 \mathrm{~g}$ \\
\hline Inqlab-91 & 90.7 a & $90.7 \mathrm{a}$ & $92.3 \mathrm{a}$ & $91.2 \mathrm{a}$ & $56.0 \mathrm{ab}$ & $56.2 \mathrm{ab}$ & $53.0 \mathrm{ab}$ & $55.0 \mathrm{abc}$ \\
\hline Mean & 80.5 & 81.2 & 81.3 & 81.0 & 50.7 & 50.4 & 49.5 & 50.2 \\
\hline
\end{tabular}

Note: Means followed by the same letter within a column are not statistically different according to DMR test at $P<0.05$. PG, Percent germination; GI, Germination index; $T_{1}$, Germination of seeds immediately after harvest; $T_{2}$, Germination of seeds kept for seven days on blotting paper before the germination test; $T_{3}, G$ Germination tests on seeds that were kept unthreshed for seven days before the germination test. 
Table 3 Analysis of variance for PG and GI in $8 \times 8$ diallel crosses of spring wheat

\begin{tabular}{lccc}
\hline \multirow{2}{*}{ Source of variation } & \multirow{2}{*}{ DF } & \multicolumn{2}{c}{ Mean square } \\
\cline { 3 - 4 } & & PG & GI \\
\hline Replication & 2 & 1.76 & 2.34 \\
Genotype & 63 & $405.11^{* *}$ & $418.10^{* *}$ \\
Error & 126 & 0.99 & 1.15 \\
CV/\% & 1.39 & & \\
\hline
\end{tabular}

Note: PG, Percent germination; GI, Germination index; ${ }^{* *}$, significant difference at $P<0.01$.

Table 4 Analysis of variance for the combining ability of percent PG and GI in $8 \times 8$ diallel crosses of spring wheat

\begin{tabular}{lccc}
\hline \multirow{2}{*}{ Source of variation } & \multirow{2}{*}{ DF } & \multicolumn{2}{c}{ Mean square } \\
\cline { 3 - 4 } & & $751.63^{* *}$ & $740.95^{* *}$ \\
\hline GCA & 7 & $62.68^{* *}$ & $50.71^{* *}$ \\
SCA & 28 & $53.25^{* *}$ & $77.45^{* *}$ \\
Reciprocal & 28 & 0.33 & 0.38 \\
Error & 126 & 11.99 & 14.61 \\
GCA/SCA & &
\end{tabular}

Note: PG, Percent germination; GI, Germination index; ${ }^{* *}$, significant difference at $P<0.01$.

Table 5 Estimates of variance components of general and specific combining abilities (GCA and SCA), reciprocal effects of PG, and GI for $8 \times 8$ diallel crosses of spring wheat

\begin{tabular}{lcc}
\hline Components of variance & PG & GI \\
\hline GCA & 43.13 & 43.19 \\
SCA & 35.01 & 28.26 \\
Reciprocal & 26.46 & 38.53 \\
Environmental & 0.33 & 0.38 \\
\hline
\end{tabular}

Note: PG, Percent germination; GI, Germination index.

whereas the crosses such as BARS-09 $\times$ Inqlab-91, Hamam-4 $\times$ BARS-09, 09FJ21 $\times$ Doukkala-12,
Hamam-4 $\times$ Hubara-2/Qafzah-21 had higher positive SCA values for PG (Table 6). The cross combinations Hubara-2/Qafzah-21 × Dharabi-11, Hamam-4 × 09FJ21, BARS-09 $\times$ Inqlab-91, Hubara-2/Qafzah-21 × 09FJ21 had higher positive GI values than other direct crosses (Table 7).

Reciprocal effects of $P G$ show that the hybrids Doukkala-12 $\times$ Inqlab-91 had maximum negative value $(-13.5)$, followed by BARS-09 $\times$ Inqlab-91 (-9.38), Dharabi-11 $\times$ Inqlab-91 (-7.95), 06FJS3013 $\times$ Inqlab-91 $(-4.82)$ and Dharabi-11 $\times$ 09FJ21 (-4.80) (Table 6). Among the rest of the crosses, the majority had positive values for PG. As far as GI values were concerned, the crosses of Doukkala-12, BARS-09, Dharabi-11 and 09FJ21 with Inqlab-91 had higher negative reciprocal effects $(-10.83,-10.70,-10.37$ and -6.60 , respectively) (Table 7). The majority of the remaining crosses had positive reciprocal effects.

\section{Discussion}

Pre-harvest sprouting resistance of wheat is assessed by its grain dormancy level, i.e., PG and GI. PG is negatively associated with the seed dormancy level or sprouting resistance $^{[31]}$. GI is a weighted indicator that gives higher weight to early germinating grain and gradually lesser weight to seeds germinating later ${ }^{[32]}$. GI is a useful measure when there is a lower grain germination due to comparatively small rainfall periods as an easy, quick and trouble-free method to measure the susceptibility to preharvest sprouting. Germination testing is a useful and easy method for assessing pre-harvest sprouting resistance of different wheat genotypes compared to the various enzymatic tests ${ }^{[27]}$ and $\mathrm{Wu}$ and Carver ${ }^{[21]}$ demonstrated that PG has good association with field assessment of sprout damage.

Temperature and moisture are the key environmental aspects that affect pre-harvest sprouting, especially during the late maturity stage of wheat ${ }^{[33-35]}$. In 2011, there was $100 \mathrm{~mm}$ of rainfall on a single day (25 April), after plant

Table 6 Estimates of general combining ability effects (diagonal values), specific combining ability effects (above the diagonal), and reciprocal effects (below the diagonal) for percent germination in $8 \times 8$ diallel crosses of spring wheat

\begin{tabular}{lrrrrrrrr}
\hline Genotype & P-1 & P-2 & P-3 & P-4 & P-5 & P-6 & P-7 & P-8 \\
\hline P-1 & 6.55 & 2.79 & -2.38 & -2.97 & 1.25 & -4.17 & 2.88 & -2.34 \\
P-2 & -0.87 & 2.97 & 2.72 & 2.26 & -2.22 & -9.97 & -7.37 & 2.51 \\
P-3 & 1.05 & 0.13 & 1.12 & -1.92 & -6.10 & -0.65 & -3.73 & -1.81 \\
P-4 & 1.38 & 3.57 & -0.03 & 4.31 & -0.23 & 1.88 & -2.16 & -5.47 \\
P-5 & 2.72 & -2.10 & -4.80 & -0.55 & 3.45 & 2.80 & 0.32 & -7.16 \\
P-6 & 10.50 & 1.02 & 5.85 & 8.43 & -0.10 & -9.08 & -1.53 & -2.35 \\
P-7 & -0.23 & -3.20 & -1.77 & 6.72 & 4.93 & 4.07 & -12.39 & 3.50 \\
P-8 & 1.18 & -0.68 & -7.95 & -4.82 & -4.43 & -13.48 & -9.38 & 3.08 \\
\hline
\end{tabular}

Note: P-1, Hamam-4; P-2, Hubara-2/Qafzah-21; P-3, Dharabi-11; P-4, 06FJS3013; P-5, 09FJ21; P-6, Doukkala-12; P-7, BARS-09; P-8, Inqlab-91. 
Table 7 Estimates of general combining ability effects (diagonal values), specific combining ability effects (above the diagonal values), and reciprocal effects (below the diagonal values) for germination index in $8 \times 8$ diallel crosses of spring wheat

\begin{tabular}{lrrrrrrrr}
\hline Genotype & P-1 & P-2 & P-3 & P-4 & P-5 & P-6 & P-7 \\
\hline P-1 & 6.61 & 2.67 & -2.80 & -2.50 & 3.64 & -0.35 & 0.01 & -1.42 \\
P-2 & -0.37 & 2.53 & 4.52 & 1.58 & 2.89 & -9.71 & -9.23 \\
P-3 & 2.12 & 0.05 & 1.52 & 1.24 & -4.64 & -1.24 & -4.31 \\
P-4 & -0.23 & 2.13 & 2.57 & 6.03 & -0.23 & 1.67 & -1.25 & -3.21 \\
P-5 & 1.45 & -1.55 & -5.37 & 1.63 & 2.11 & -1.72 & -3.58 & -5.31 \\
P-6 & 13.42 & 2.87 & 3.72 & 10.32 & 5.45 & -10.41 & -0.44 \\
P-7 & 10.40 & 1.15 & 0.45 & 11.67 & 7.25 & 2.30 & -0.90 \\
P-8 & 2.40 & -1.30 & -10.37 & 0.55 & -6.60 & -10.83 & -10.81 \\
\hline
\end{tabular}

Note: P-1, Hamam-4; P-2, Hubara-2/Qafzah-21; P-3, Dharabi-11; P-4, 06FJS3013; P-5, 09FJ21; P-6, Doukkala-12; P-7, BARS-09; P-8, Inqlab-91.

maturity and another $9 \mathrm{~mm}$ on 2 May. The average daily temperature was $22.6^{\circ} \mathrm{C}$ with $80 \% \mathrm{RH}$ during days of cloudy weather. Such sudden weather changes are not normal. The climate of the Fatehjang region is generally favorable for screening pre-harvest sprouting responses of wheat genotypes under natural rainfall conditions. Anderson et al. ${ }^{[36]}$ reported that pre-harvest sprouting resistance can be tested under natural or artificial rainfall conditions. For these reasons, sprouting resistance of 15 wheat genotypes were evaluated under natural conditions in this region. Wet wheat spikes from these genotypes were harvested immediately after rainfall to assess their PG and GI under controlled conditions. On average, $\mathrm{PG}$ values for $T_{2}$ and $T_{3}$ were higher than $T_{1}$, while $T_{1}$ and $T_{2}$ values were higher than $T_{3}$ values for GI. This variation in PG could be conditioned by temperature as germination tests were carried out for $T_{2}$ and $T_{3}$ after one week storage at room temperature ${ }^{[37]}$.

Threshed seeds and whole spikes were also kept at room temperature for 1 week to study the effect of wet awns on sprouting, but no significant differences in $P G$ was observed between $T_{2}$ and $T_{3}$ (Table 2). This finding was consistent with the results of Gavazza et al. ${ }^{[6]}$ but differed from those of Harrington ${ }^{[38]}$, who showed that unthreshed seeds took 20 days longer to germinate than threshed seeds. Many spike or plant attributes and mechanisms, such as ear type, seed coat, water uptake of the seed, germination inhibitors in seeds, drying rate of the ear, $\alpha$-amylase synthesis, the rate of imbibition, spike orientation, smooth wax and glossy surfaces, starch sensitivity, soil properties, day length, drought, response to gibberellic acid and intensity of light, are related to sprouting susceptibility ${ }^{[5,7,14,39-42]}$.

The genotypes Doukkala-12, BARS-09, 09FJ17, Ouassou-20 and NARC-09 showed lower values for GI and PG compared to the other genotypes. The genotypes Hamam4, Dharabi-11, Inqlab-91, 06FJS3013 and CH-50 showed higher values of GI and PG compared to the other genotypes, so had a greater susceptibility to pre-harvest sprouting (Table 2). Inqlab-91 showed the highest PG but a moderate to high GI level. Groos et al. ${ }^{[10]}$, Ogbonnaya et al. ${ }^{[43]}$ and Yucel et al. ${ }^{[4]}$ reported significantly lower values of PG and GI in red kernel cultivars than in white ones, which was also recorded in our study, indicating a relationship between grain color and pre-harvest sprouting resistance.

The association between red color and pre-harvest sprouting resistance is expected due to pleiotropic effects (genetic linkage) of the genes governing grain color, which occur on the short arm of chromosome $5 \mathrm{~A}$ of wheat ${ }^{[10,43,44]}$. The results of our study are consistent with a linkage between red kernel type and pre-harvest sprouting resistance. Wheat cultivars, BARS-09, 09FJ17, Doukkala-12, Ouassou-20 and NARC-09, showed preharvest resistance, which can provide breeding materials for development of white kernel wheat genotypes resistant to pre-harvest sprouting. However, due to limited resources a limited number of genotypes were examined for preharvest resistance. Although some of the genotypes were found to possess desirable traits, evaluation of more genotypes will be needed for efficient use in breeding programs.

Five white kernel wheat cultivars, Dharabi-11, 06FJS3013, 09FJ21, BARS-09 and Inqlab-91 (susceptible) and three red kernel wheat cultivars, Hamam-4, Hubara-2/ Qafzah-21 and Doukkala-12 (resistant), from the germination test results, were selected for diallel crossing to assess the inheritance and the combining ability of sprouting resistance in the $F_{1}$. In this assessment both additive and non-additive gene effects were found; however, due to high GCA variance, additive gene action was quite high. The genetic gains in traits linked to pre-harvest sprouting resistance in cereals is primarily governed by additive genes (multiple genes) ${ }^{[1,45,46]}$. A similar relationship between pre-harvest sprouting resistance and additive gene action was also reported by Gao et al. ${ }^{[5]}$.

Positive combining ability is an indicator of an increase in a trait under study and a negative result indicates a decrease in the performance of the trait ${ }^{[47]}$. In this study we assessed the sprouting resistance by GI and PG. The 
genotypes with low PG and GI have a dormancy period. Therefore, in this case, a high or positive value of combining ability indicated a susceptibility to pre-harvest sprouting and vice versa.

To transfer desired characters to offspring, those parents that have a good combining ability should be included in a compound breeding approach ${ }^{[48]}$. Yildirim et al. ${ }^{[47]}$ stated that the additive genetic variation is the main choice in formalizing a selection approach in a wheat breeding program. Among the genotypes, Doukkala-12 and BARS09, showed significant negative GCA values for PG and GI. In the case of self-pollinated crops, SCA conditioned by heterosis has minimal effect on the development of any specific characters ${ }^{[48]}$. The hybrids with negative SCA values or higher sprouting resistance were Hubara-2/ Qafzah-21 $\times$ Doukkala-12 and Hubara-2/Qafzah-21 $\times$ BARS-09, which had maximum negative SCA effects for both PG and GI (Tables 6-7).

A well-built cytoplasmic effect on both factors is displayed by significant reciprocal effects (Table 5). Inqlab-91 could be utilized as a male parent while having Doukkala-12, BARS-09 and Dharabi-11 as females. The parents used in the crosses had negative GCA values (Doukkala-12 and BARS-09), which is an indication that the hybrids of these parents would produce wanted transgressive segregants. Doukkala-12 and BARS-09 were found to be the best parents for both general and specific combining abilities.

Pre-harvest sprouting susceptibility is considered primarily to be due to a genetic mechanism, but is also affected by the environment (less than 6\%) during seed growth $^{[19,31,33]}$. Low heritability, and being a self-pollinated crop producing single generation a year, makes it difficult to breed wheat for pre-harvest sprouting resistance ${ }^{[49]}$. Although selection is restricted to one generation in a year ${ }^{[36]}$, two generations a year can be produced by shuttle breeding. In addition, strong environmental influence on the sprouting resistance has been reported by Zanetti et al. ${ }^{[50]}$. This also makes it difficult to select desirable plant materials from segregating offspring. Jiang and $\mathrm{Xiao}^{[1]}$ reported that certain local landraces and wild ancestors of modern hexaploid wheat can be used in production of white kernel wheat cultivars that would be more resistant to pre-harvest sprouting. Many scientists have found that Aegilops tauschii (the D-genome donor of bread wheat) has a high deviation for sprouting resistance and QTLs for sprouting resistance are located on almost every chromosome ${ }^{[16,51-54]}$. Similarly, Lan et al. ${ }^{[55]}$ also found that $A$. tauschii had $0 \%$ germination of both threshed kernels and intact spikes. An artificial amphiploid 'RSP' $(2 n=42$, AABBDD) (T. turgidum-A. tauschii) with strong pre-harvest sprouting resistance is an example of an artificially synthesized hexaploid wheat made from crossing A. tauschii and T. turgidum (tetraploid) wheat ${ }^{[51]}$.

The results of the diallel crosses in this study contribute useful data. Doukkala-12 and BARS-09 can be used for the development of pre-harvest sprouting resistance. Doukkala-12 is a red and bold seeded wheat cultivar of Mediterranean origin with good production potential ${ }^{[48]}$ and also performs well in barani areas. BARS-09, on the other hand, a local wheat cultivar well adapted to this rainfed region, has white kernels, high tillering, good quality and high yield. BARS-09 is more resistant to preharvest sprouting as it possesses tightly held spikelets, which reduces rainfall contact. These wheat cultivars could easily be exploited in an effective manner in a breeding program to develop wheat with moderate dormancy periods and resistance to pre-harvest sprouting.

In Pakistan, unluckily, breeding and selection for preharvest sprouting resistance in white kernel wheat has receive little attention in recent years. Due to climate change, rains occur during the harvest of wheat in the rainfed or barani tract of Pakistan, therefore it is essential to develop new cultivars that are resistant to pre-harvest sprouting. Another factor is the correlation of seed color and sprouting resistance. Red kernel wheat is usually more resistant than white types, but it is difficult to select for genes that are linked to sprouting resistance in red kernel genotypes. If molecular studies can identify markers for the sources of pre-harvest sprouting resistance this information would benefit future breeding programs.

\section{Conclusions}

The results of this study will be useful to the breeders working on pre-harvest sprouting resistance, especially those working with wheat in barani areas of Pakistan. The data will allow breeders to make selections from the breeding material they have and use them in the improvement of pre-harvest sprouting resistance in white kernel wheat genotypes. In particular, Inqlab-91, BARS-09 and Dharabi-11 are the most promising cultivars that could be used for pre-harvest sprouting resistance in white kernel cultivars, while Doukkala-12 can be used as foreign parent for improvement in a breeding bank.

Acknowledgements This work was supported by Government of Punjab, Pakistan and Higher Education Commission of Pakistan.

Compliance with ethics guidelines Muhammad Zeeshan, Waheed Arshad, Muhammad Imran Khan, Shiraz Ali, Ali Nawaz, Amina Batool, Muhammad Tariq, Muhammad Imran Akram, and Muhammad Amjad Ali declare that they have no conflicts of interest or financial conflicts to disclose.

This article does not contain any studies with human or animal subjects performed by any of the authors.

\section{References}

1. Jiang G L, Xiao S. Factorial cross analysis of pre-harvest sprouting resistance in white wheat. Field Crops Research, 2005, 91(1): 63-69

2. Bassoi M C, Flintham J, Riede C R. Analysis of preharvest 
sprouting in three Brazilian wheat populations. Pesquisa Agropecuária Brasileira, 2006, 41(4): 583-590

3. Chao S, Xu S S, Elias E M, Faris J D, Sorrells M E. Identification of chromosome locations of genes affecting preharvest sprouting and seed dormancy using chromosome substitution lines in tetraploid wheat (Triticum turgidum L.). Crop Science, 2010, 50: 1180-1187

4. Chastain T G, Klepper B L, Wilkins D E. Relationship of wheat seed sprouting severity, planting depth and seed treatment to emergence and yield. Crop Science, 1994, 34(2): 508-513

5. Gao X, Hu C H, Li H Z, Yao Y J, Meng M, Dong J, Zhao W C, Chen Q J, Li X Y. Factors affecting pre-harvest sprouting resistance in wheat (Triticum aestivum L.): a review. Journal of Animal and Plant Science, 2013, 23(2): 556-565

6. Gavazza M I A, Bassoi M C, de Carvalho T C, Filho J C B, Panobianco M. Methods for assessment of pre harvest sprouting in wheat cultivars. Pesquisa Agropecuária Brasileira, 2012, 47(7): 928-933

7. Himi E, Mares D J, Yanagisawa A, Noda K. Effect of grain color gene $(\mathrm{R})$ on grain dormancy and sensitivity of the embryo to abscisic acid (ABA) in wheat. Journal of Experimental Botany, 2002, 53 (374): 1569-1574

8. Morad M M, Rubenthaler G L. Germination of soft white wheat and its effect on flour fractions, bread baking, and crumb firmness. Cereal Chemistry, 1983, 60(6): 413-417

9. Trethowan R M. Application of physiology in wheat breeding. In: Reynolds M P, Ortiz-Monasterio J I, AMcNab, eds. Preharvest Sprouting Tolerance (eds.). Mexico: CIMMYT Wheat Program, 2001, 145-147

10. Groos C, Gay G, Perretant M R, Gervais L, Bernard M, Dedryver F, Charmet G. Study of the relationship between pre-harvest sprouting and grain color by quantitative trait loci analysis in a whitexred grain bread-wheat cross. Theoretical and Applied Genetics, 2002, 104(1): 39-47

11. Mansour K. Sprout damage in wheat and its effect on wheat flour products. In: Pre-harvest Sprouting in Cereals. Walker-Simmons M K, Ried J L, eds. Saint Paul: The American Association of Cereal Chemists, 1993, 8-9

12. Humphreys D G, Noll J. Methods for characterization of pre-harvest sprouting tolerance in a wheat breeding program. Euphytica, 2002, 126(1): 61-65

13. Bainotti C, Cuniberti M, Masiero B, Donaire G, Gómez D, Reartes F, Salines J, Formica M, Fraschina J, Nisi J, Mir L, Berra O. Characterization of wheat cultivars for pre-harvest sprouting. Agriscientia, 2009, 26(1): 29-33

14. Cai J X, Chen W. Study on the physiological biochemistry of preharvest sprouting and scanning electron microscopy of glume in rice. Agricultural Science and Technology, 2008, 9(1): 75-80

15. Derera N F. Breeding for preharvest sprouting in tolerance. In: Preharvest Field Sprouting in Cereals. Derera D F, ed. Boca Raton, Florida: CRC Press Incorporated, 1989, 111-128

16. Flintham J E. Different genetic components control coat-imposed and embryo-imposed dormancy in wheat. Seed Science Research, 2000, 10(1): 43-50

17. Mares D, Mrva K, Cheong J, Williams K, Watson B, Storlie E, Sutherland M, Zou Y. A QTL located on chromosome 4A associated with dormancy in white- and red-grained wheats of diverse origin. Theoretical and Applied Genetics, 2005, 111(7): 1357-1364

18. Yang J H, Yu Y X, Cheng J S, Tan X L, Shen W P. Study on the pre harvest sprouting tolerance in Triticum aestivum ssp. yunnanense King. Journal of Triticeae Crops, 2011, 31(4): 747-752

19. Gubler F, Millar A A, Jacobsen J V. Dormancy release, ABA and pre-harvest sprouting. Plant Biology, 2005, 8(2): 183-187

20. Andreoli C, Bassoi M C, Brunetta D. Genetic control of seed dormancy and pre-harvest sprouting in wheat. Scientia Agrícola, 2006, 63(6): 564-566

21. Wu J, Carver B F. Sprout damage and preharvest sprout resistance in hard white winter wheat. Crop Science, 1999, 39(2): 441-447

22. Shorter S C, Munro C A, Hodgkinson J. Predicting preharvest sprouting susceptibility in New Zealand wheat cultivars. Euphytica, 2005, 143(3): 309-312

23. Torada A, Amano Y. Effect of seed coat color on seed dormancy in different environments. Euphytica, 2002, 126(1): 99-105

24. Graybosch R A, St. Amand P, Bai G H. Evaluation of genetic markers for prediction of preharvest sprouting tolerance in hard white winter wheats. Plant Breeding, 2013, 132(4): 359-366

25. Griffing B. Concept of general and specific combining ability in relation to diallel crossing systems. Australian Journal of Biological Sciences, 1956, 9(4): 463-493

26. Paterson A H, Sorrells M E, Obendorf R L. Methods of evaluation for preharvest sprouting resistance in wheat breeding programs. Canadian Journal of Plant Science, 1989, 69(3): 681-689

27. Hagemann M G, Ciha A J. Evaluation of methods used in testing winter wheat susceptibility to preharvest sprouting. Crop Science, 1984, 24(2): 249-254

28. Steel R G D, Torrie J H, Dickey D A. Principles and procedures of statistics: a biometrical approach. 3rd Ed. New York, USA: McGraw Hill Book Company, Incorporated, 1997, 400-428

29. Muhammad F. Statistical Methods and Data Analysis. Faisalabad, Pakistan: Kitab Markaz, 2005, 97-402

30. Duncan D B. Multiple range and multiple F test. Biometrics, 1955, 11(1): $1-42$

31. Biddulph T B, Plummer J A, Setter T L, Mares D J. Seasonal conditions influence seed dormancy and preharvest sprouting tolerance of wheat (Triticum aestivum L.) in the field. Field Crops Research, 2008, 107(2): 116-128

32. Reddy L V, Metzger R J, Ching T M. Effect of temperature on seed dormancy of wheat. Crop Science, 1985, 25(3): 455-458

33. Gao J B, Pan J M, Lu Q W, Pan J F, Xu M G. Influencing factors of wheat sprout in field and its prevention measures. Seed Science and Technology, 2006, 25: 75-77

34. Hilhorst H W M. A critical update on seed dormancy. I. Primary dormancy. Seed Science Research, 1995, 5(1): 61-73

35. Yanagisawa A, Nishimura T, Amano Y, Torada A, Shibata S. Development of winter wheat with excellent resistance to preharvest sprouting and rain damage. Euphytica, 2005, 143(3): 313318

36. Anderson J A, Sorrells M E, Tanksley S D. RFLP analysis of genomic regions associated with resistance to pre-harvest sprouting in wheat. Crop Science, 1993, 33(3): 453-459

37. Mares D J. Pre-harvest sprouting in wheat. Influence of cultivar, rainfall and temperature during grain ripening. Australian Journal of 
Agricultural Research, 1993, 44(6): 1259-1272

38. Harrington J B. Testing cereal varieties for dormancy. Scientia Agrícola, 1949, 29(11): 538-550

39. He Z T, Chen X L, Han Y P. Progress on preharvest sprouting resistance in white wheat. Journal of Triticeae Crops, 2000, 20(1): $84-87$

40. King R W, von Wettstein-Knowles P. Epicuticular waxes and regulation of ear wetting and pre-harvest sprouting in barley and wheat. Euphytica, 2000, 112(2): 157-166

41. Rodriguez M V, Margineda M, Gonzalez-Martin, Insausti P, Benech-Arnold R L. Predicting pre-harvest sprouting susceptibility in barley. A model based on temperature during grain filling. Agronomy Journal, 2001, 93(5): 1071-1079

42. Wang X G, Ren J P, Yin J. The mechanism on wheat pre-harvest resistant sprouting. Chinese Agricultural Science Bulletin, 2008, 24 (1): 243-250

43. Ogbonnaya F C, Imtiaz M, DePauw R M. Haplotype diversity of preharvest sprouting QTLs in wheat. Genome, 2007, 50(2): 107-118

44. Yucel C, Baloch F S, Hatipoglu R, Ozkan H. Genetic analysis of preharvest sprouting tolerance in bread wheat (Triticum aestivum $\mathrm{L}$. emend. Thell.). Turkish Journal of Agriculture and Forestry, 2011, 35(1): 9-22

45. Barnard A, van Deventer C S, Maartens H. Genetic variability of preharvest sprouting - the South Africa situation. Euphytica, 2005, 143(3): 291-296

46. Herrmann M. A diallel analysis of various traits in winter triticale. Plant Breeding, 2007, 126(1): 19-23

47. Yildirim M, Gezginç H, Paksoy A H. Hybrid performance and heterosis in $\mathrm{F}_{1}$ offspring of triticale ( $\times$ Triticosecale Wittm.). Turkish Journal of Agriculture and Forestry, 2014, 38(6): 877-886

48. Yiicel C, Baloch F S, Ozkan H. Genetic analysis of some physical properties of bread wheat grain (Triticum aestivum L. em Thell.). Turkish Journal of Agriculture and Forestry, 2009, 33(6): 525-535

49. Lawson W R, Godwin I D, Cooper M, Brennan P S. Genetic analysis of preharvest sprouting tolerance in three wheat crosses. Australian Journal of Agricultural Research, 1997, 48(2): 215-221

50. Zanetti S, Winzeler M, Keller M, Keller B, Messmer M. Genetic analysis of pre-harvest sprouting resistance in a wheat $\times$ spelt cross. Crop Science, 2000, 40(5): 1406-1417

51. Lan X J, Wei Y M, Liu D C, Yan Z H, Zheng Y L. Inheritance of seed dormancy in Tibetan semi-wild wheat accession Q1028. Journal of Applied Genetics, 2005, 46(2): 133-138

52. Kottearachchi N S, Uchino N, Kato K, Miura H. Increased grain dormancy in white-grained wheat by introgression of preharvest sprouting tolerance QTLs. Euphytica, 2006, 152(3): 421-428

53. Ren X B, Lan X J, Liu D C, Wang J L, Zheng Y L. Mapping QTLs for pre-harvest sprouting tolerance on chromosome $2 \mathrm{D}$ in a synthetic hexaploid wheat $\times$ common wheat cross. Journal of Applied Genetics, 2008, 49(4): 333-341

54. Munkvold J D, Tanaka J, Benscher D, Sorrells M E. Mapping quantitative trait loci for preharvest sprouting resistance in white wheat. Theoretical and Applied Genetics, 2009, 119(7): 1223-1235

55. Lan X J, Zheng Y L, Wei Y M, Liu D C, Yan Z H, Zhou Y H. Tolerant mechanism and chromosome location of genes controlling sprouting tolerance in Aegilops tauschii Cosson. Agricultural Sciences in China, 2002, 1(3): 265-268 